\title{
Jóvenes, cultura y política en América Latina: algunos trayectos de sus relaciones, experiencias y lecturas (1960-2000). Alvarado y Vommaro (comp.) Editorial Homo Sapiens, Santa Fe, Argentina, 2010
}

\section{Nazareno Bravo*}

\author{
Nivel: Reseña bibliográfica \\ Fecha de recepción: 20 de julio de 2011 \\ Fecha de aprobación: 27 de agosto de 2011
}

El libro que se presenta es resultado de la labor investigativa de un grupo de intelectuales latinoamericanos agrupados en el Grupo de Trabajo de CLACSO: "Juventud y nuevas prácticas políticas en América Latina". El volumen está estructurado en diez capítulos que presentan, por un lado, detallados estados del arte de la producción académica sobre juventud en Argentina, Venezuela, Uruguay, Colombia, Brasil y Chile; por el otro lado, se profundizan algunas áreas temáticas específicas como juventud rural (en Brasil), pandillas (en América Latina) y nuevas prácticas políticas (para los casos de Argentina, Brasil y Chile).

Una de las principales conclusiones que pueden obtenerse de esta obra es la necesidad de historizar y situar la construcción de la categoría juventud, basada en un objeto de estudio no siempre visible como tal y en muchos casos abordado desde diversas perspectivas lógicas y contextos epistemológicos a lo largo de la época contemporánea. Se destaca, entonces, la voluntad de quebrar cierta uniformidad comprensiva que muchas veces ha

* Doctor en Ciencias Sociales por FLACSO. Instituto de Ciencias Humanas, Sociales y Ambientales del Consejo Nacional de Investigaciones Científicas y Técnicas de Argentina.nbravo@mendoza-conicet.gob.ar 
soportado dicha categoría. De allí la importancia de reconocer, además de la complejidad y dinamismo de la misma, los cruces con variables tales como clase social, género o etnia.

En el primero de los estudios presentados, el único referido al caso argentino, se plantean buena parte de las concepciones y discusiones teóricas que atraviesan las indagaciones del grupo de trabajo. Se remarca el carácter relacional del concepto juventud, en tanto compleja construcción identitaria en la que intervienen distintos actores sociales -los propios jóvenes en sus espacios de participación pero también el Estado, los medios de comunicación, la academia, etcétera-. Surge con claridad lo conflictivo de aquella construcción, enmarcada en relaciones de poder y estrategias de dominación social que necesariamente deben ser tenidas en cuenta para realizar un análisis crítico y creativo. Este capítulo plantea el derrotero de la relación entre juventud y participación política, iniciando el recorrido a finales de la década de 1960 hasta alcanzar el año 2008, lo que implica momentos de radicalización, descreimiento, construcciones divergentes y una aparente reinstitucionalización en la actualidad.

El capítulo dedicado al caso venezolano plantea una interesante discusión respecto de la idea de generación, en tanto representación hegemónica que se construye sobre el rol crítico y democratizador que los jóvenes cumplirían en aquel sistema político. Anclado en los estudios sobre los estudiantes en el proceso que encabeza el presidente Chávez, se muestra cómo se ha ido revalorizando el papel que jugó la generación de 1928 en la democratización institucional. Más allá del debate político, el trabajo muestra las limitaciones que para los estudios sociales y hasta para la política, acarrea el hecho de construir una épica continuidad intergeneracional y descuidar las diferentes miradas y prácticas que prevalecen en una y otra juventud.

También con el movimiento estudiantil como punta de lanza para los estudios sobre juventud (hecho que se repite en otras latitudes) se presentan los dos capítulos dedicados al caso co- 
lombiano. Se destaca la discusión sobre los modos de participación política que quedan por fuera de los planes estatales. La vinculación entre cambios culturales y políticos y el desarrollo de nuevas etapas de producción del capital, se traducen en la tensa coexistencia e interacción entre modos de concebir lo político. Desde las grietas del sistema institucionalizado y su forma de concebir ciudadanía, se cuelan novedosas relaciones sociales y vías de participación enarboladas por jóvenes en movimientos sociales y culturales de Colombia. Este capítulo puede ser vinculado con el que se dedica a las nuevas formas de participación política en Chile, en el que se plantean una serie de hipótesis para explicar la supuesta baja participación juvenil. Lo que se busca, en ambos casos, es reconocer la emergencia de modos de agregación y participación por canales no institucionalizados, horizontales, basistas y autogestionados, entre otras características.

El recorrido realizado por el concepto juventud en buena parte por los estudios sociales en el Continente, queda reflejado con claridad en el capítulo dedicado al Uruguay. Puede vislumbrarse allí, la prevalencia de los diversos paradigmas que lograron imponerse en la academia oriental: desde un tratamiento puramente estadístico en los años 40 y 50 del siglo pasado, a una aproximación cualitativa e interpretativa a partir de los 90 y destacando, entre otras, la influencia funcional-estructuralista durante los 70 -bajo la cual los jóvenes son entendidos como grupo social en etapa de socialización o moratoria, otra de las palabras claves en la genealogía de los estudios sobre juventud.

Como se dijo, el libro posee además de los estados del arte mencionados, algunos capítulos dedicados a profundizar algunas particularidades de los estudios sobre juventud. Pueden nombrarse aquí, además de las ya citadas nuevas prácticas políticas, las presentaciones sobre juventud rural y urbana en Brasil (capítulo 2 y 10 respectivamente), pandillas en América Latina (capítulo 7). 
Parece importante destacar que la postulación de los jóvenes como sujetos políticos -aspecto no siempre presente y que inclusive muchas veces es negado tanto en los análisis teóricos como en las políticas públicas-, obliga a una revisión en paralelo de la propia categoría política. Sin lugar a dudas, la mayor o menor visibilidad de los jóvenes como actores políticos ha dependido en gran parte de lo que es considerado como tal, ya se trate de definiciones menos o más institucionalizadas o de prácticas reconocidas como políticas.

La necesaria mirada sobre lo político permite, a su vez, un abordaje complejo sobre el rol del Estado en la edificación de ciudadanía a través de políticas públicas dirigidas hacia los jóvenes, con la educación como espacio paradigmático pero atendiendo también a otros modos de nombrar, convocar y actuar hacia la juventud. Emerge aquí otra de las aristas que el volumen presentado toma en cuenta, y que es el papel que juega la academia (podría agregarse en este plano, el rol de los medios masivos y la industria cultural) en la visibilización y caracterización de un sujeto juvenil. Tanto las tendencias teóricas como las opciones metodológicas, han ido condicionando los modos de analizar científicamente, pero también, de construir sentido común en torno a los jóvenes. Sin embargo, la lógica de construcción y ubicación de la juventud como objeto de estudio, comparte elementos fundamentales con otras problemáticas sociales y con los modos de abordarlas que se vuelven hegemónicos. De allí que la obra permita, en definitiva, una interesante discusión teórica que excede en muchos de sus pasajes los recorridos realizados en el desentrañamiento de la categoría juventud.

En este marco conviene resaltar la advertencia que los autores del capítulo argentino realizan para cuestionar una sociología de la desintegración social, es decir, el análisis social reciente basado en lo que los jóvenes "no tienen" o "ya no son". Esto, sin descuidar el enorme impacto que tuvieron y tienen las transformaciones estructurales que supuso la instauración del neoliberalismo a 
lo largo del Continente. Parece necesario cuestionar creativamente ciertas nociones que se fueron estableciendo para comprender aquel proceso.

Por un lado -justamente teniendo en cuenta lo profundo de las transformaciones- resulta central tomar en cuenta la voz de los propios jóvenes, esto es, aproximarse a una comprensión de los modos de experimentar su propia situación. Por el otro, reconocer el surgimiento de vías de politización extra-institucionales, vinculado a espacios de organización y participación (considerados "culturales" o "sociales" en muchos casos) que posibilitan definiciones y posicionamientos conjuntos sobre problemáticas de raigambre política. En cierto sentido, se refuerza la noción de la existencia de vías de politización basadas en prácticas participativas en un sentido amplio.

En definitiva, el libro reseñado es resultado de una ardua labor de investigación llevada a cabo en distintos puntos de América Latina, lo que permite reconocer trayectos, disputas y perspectivas en un campo de estudio que ha ido adquiriendo relevancia costosamente, pero que en la actualidad adquiere una importancia central para la comprensión de los procesos sociales contemporáneos en nuestro Continente. 